\title{
High quality data are the key to understanding inequalities in cancer outcomes for Aboriginal and Torres Strait Islander Australians
}

\author{
David M Roder', Elizabeth Buckley²
}

A comprehensive evidence base for informing efforts to improve services requires linked national data

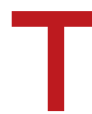

he study by Condon and colleagues in this issue of the MJA confirms past reports of the uncertain validity of reported cancer data for Aboriginal and Torres Strait Islander people resulting from poor recording of Indigenous Australian status in source databases. ${ }^{1,2}$ To improve the evidence base, the Australian Institute of Health and Welfare has limited analyses of cancer incidence among Aboriginal and Torres Strait Islander Australians to four Australian states and territories - the Northern Territory, Queensland, New South Wales and Western Australia - as their data are regarded as being of better quality. ${ }^{2}$

This study by Condon et al analysed high quality, validated data on Aboriginal and Torres Strait Islander status from the NT Cancer Registry. ${ }^{1}$ Their results confirm earlier findings that age-standardised all-cancer incidence rates are slightly lower for Indigenous Australians than for other Australians ${ }^{2,3}$ - although more recent data suggest negligible differences between the two groups $^{4}$ - but poorer survival in Indigenous Australians, and substantially elevated cancer mortality. ${ }^{2,4-6}$

The study published in this issue confirms the relatively low incidence among Aboriginal and Torres Strait Islander Australians of cancers of the breast, colon-rectum, prostate and skin (melanoma) - cancers usually associated with average or above average survival - and, conversely, the elevated incidence of cancers of the cervix, and also of the lung, head and neck, other tobacco-related sites, and liver - cancers generally associated with average or below average survival. ${ }^{3,5}$

The study by Condon et al also confirms findings from another investigation that analysed data on survival trends from a single registry, the Queensland Cancer Registry. ${ }^{6}$ Survival trends data from a single registry source may be less vulnerable to methodological bias than data from multiple sources. Condon and his colleagues found that age-standardised incidence rates for female breast, colorectal and prostate cancers among Aboriginal and Torres Strait Islander people had increased between 1991 and 2012, possibly reflecting changing social and economic circumstances. ${ }^{1}$ These are leading incidence cancers among Australians overall, and the reported increases probably reflect the increasing adoption by Indigenous people of lifestyles similar to those of other Australians, replacing their traditional practices. ${ }^{1,7}$ These trends have important implications for planning services, including the priorities to be given to screening, other early detection measures, and primary prevention.
Conversely, the incidence of cervical cancer among Aboriginal and Torres Strait Islander women, while still relatively high, has decreased following increased participation in screening programs. ${ }^{7,8}$ It is encouraging to see the increases in survival from most common cancers for Indigenous Australian patients, despite overlapping confidence limits due to small case numbers.

While the results of this study are directly relevant to the NT, their representativeness for other Aboriginal and Torres Strait Islander populations is less clear. ${ }^{3,9}$ The estimated 13\% of Australia's Indigenous population who live in the NT are, in some respects, atypical. A disproportionately high proportion of these people live in geographically remote and lower socio-economic areas, and the fraction following traditional lifestyles may have significant effects on cancer risks and outcomes. ${ }^{1,7,10}$ This may lead to lower risks of cancers that are more common in the general Australian population, such as those of the female breast, prostate, and colon-rectum. ${ }^{1,2,5}$

Confirming lower cancer-specific survival for NT Aboriginal and Torres Strait Islander patients is important, but without data on disease stage at diagnosis, other prognostic factors, comorbidities and treatment, the underlying reasons for the differences are difficult to determine. Self-reported data are also needed for assessing perceptions of the value of treatment, the cultural appropriateness of services, and barriers to treatment.

Cancer Australia is promoting the increased availability of data for national cancer control indicators across Australia, including data on stage, treatment, and recurrence. ${ }^{11}$ Collecting patient-reported experiences would also be desirable. Australian researchers have already shown the value for population health and health system surveillance of linking data from cancer registries, inpatient statistics, and radiotherapy centres in New South Wales, Queensland, and some other jurisdictions. ${ }^{12}$ Australia urgently needs an organised, linked data network of this type, complemented by clinical quality registries, to identify service gaps for all Australians, but especially for Aboriginal and Torres Strait Islander people and other priority groups. ${ }^{12}$ Linked national data, with improved recording of Indigenous status, is necessary for producing a comprehensive evidence base for informing efforts to improve services.

High quality data and research, exemplified by the NT study reported in this issue of the $M J A$, will continue to play a central role in confirming broader national data and providing more comprehensive local evidence. By identifying Aboriginal and Torres Strait Islander and other priority groups in special need, the nature of their needs, and self-reported barriers to accessing services, the evidence for crafting appropriate health service responses will be strengthened. 
Acknowledgements: We gratefully acknowledge the funding support of National Health and Medical Research Council Program Grant 0631946.

Competing interests: No relevant disclosures.

Provenance: Commissioned; externally peer reviewed.

(c) 2016 AMPCo Pty Ltd. Produced with Elsevier B.V. All rights reserved.

1 Condon JR, Zhang X, Dempsey K, et al. Trends in cancer incidence and survival for Indigenous and non-Indigenous people in the Northern Territory. Med J Aust 2016; 205: 454-458.

2 Australian Institute of Health and Welfare. Cancer in Australia: an overview 2014 (AlHW Cat. No. CAN 88; Cancer Series No. 90). Canberra: AlHW, 2015. http://www. aihw.gov.au/publication-detail/?id=60129550047 (accessed Aug 2016).

3 Zhang $X$, Condon JR, Rumbold AR, et al. Estimating cancer incidence in Indigenous Australians. Aust N Z J Public Health 2011; 35: 477-485.

4 Australian Institute of Health and Welfare. Cancer in Indigenous Australians [website]. Updated 2016. http://www.aihw.gov.au/cancer/indigenous-australians/ (accessed Sept 2016)

5 Condon JR, Zhang X, Baade P, et al. Cancer survival for Aboriginal and Torres Strait Islander Australians: a national study of survival rates and excess mortality. Popul Health Metr 2014; 12: 1.
6 Baade PD, Dasgupta P, Dickman PW, et al. Quantifying the changes in survival inequality for Indigenous people diagnosed with cancer in Queensland, Australia. Cancer Epidemiol 2016; 43: 1-8.

7 Cunningham J, Rumbold AR, Zhang X, Condon JR. Incidence, aetiology, and outcomes of cancer in Indigenous peoples in Australia. Lancet Oncol 2008; 9: 585-595.

8 Zhang X, Condon JR, Douglas F, et al. Women's cancers and cancer screening in the Northern Territory. Darwin: Department of Health, 2012. http://digitallibrary.health.nt.gov. au/prodjspui/handle/10137/540 (accessed Aug 2016).

9 Zhang X, Condon JR, Dempsey KE, Garling L. Cancer in the Northern Territory 1991-2010: incidence, mortality and survival. Darwin: Department of Health, 2014 http://digitallibrary.health.nt.gov.au/prodjspui/handle/10137/617 (accessed Aug 2016)

10 Condon JR, Warman G, Arnold L (editors). The health and welfare of Territorians 2001. Darwin: Epidemiology Branch, Territory Health Services, 2001. http://digitallibrary.health.nt.gov.au/prodjspui/handle/10137/114 (accessed Aug 2016).

11 Cancer Australia. Improving cancer data. Stage, treatment and recurrence (STaR) [website]. 2016. https://canceraustralia.gov.au/research-data/cancer-data/improvingcancer-data (accessed Aug 2016).

12 Roder DM, Fong KM, Brown MP, et al. Realizing opportunities for evidence-based cancer service delivery and research: linking cancer registry and administrative data in Australia. Eur J Cancer Care 2014; 23: 721-727. 